\title{
Theoretical and methodological basis of future teacher's praxeological culture development
}

\author{
Solonenko Anatoliy Mykolaiovych \\ Melitopol Bohdan Khmelnytskyi State Pedagogical University, Melitopol, Ukraine
}

Email address:

anato18@ukr.net

To cite this article:

Solonenko Anatoliy Mykolaiovych. Theoretical and Methodological Basis of Future Teacher's Praxeological Culture Development. Science Journal of Education. Vol. 2, No. 3, 2014, pp. 89-95. doi: 10.11648/j.sjedu.20140203.14

\begin{abstract}
The article deals with the essence and structure (intellectual, emotional, behavioral) praxeological culture of the future teachers which is presented on the basis of scientific resources analysis. The author reveals the main processes that are carried out by the teacher in the field of praxeological culture, i.e. transfer of the elements of an effective, productive cultural activities to pupils; reproduction in the form of various models of behavior situation success; creation of new forms of pedagogical work, which leads to its efficiency through innovation in pedagogy.
\end{abstract}

Keywords: Education, Praxeological Culture, the Future Teacher

\section{Introduction}

Nowadays, more and more teachers are aware of the fact that the threat to the process of cultural values formation in the society can be carried by underestimation of both the men's harmonious development in general, and their ability to efficiently use their own activities, to achieve on their basis positive and high-quality results in particular. Modern scientists understand that the development of future generations will depend on howa future teacher, who states values of socio-positive shifts in society through the implementation of certain action, will be educated.

\section{Analysis of the Last Researches and Publications on this Issue}

The main attention of contemporaries, who analyze ideas as for efficient, rational and perfect activity of future teachers, is focused on the formation of their personal development as the main educational objective (I. Bekh, G.Pustovit and others), the formation of experience of solving praxeological situations in the process of education (B. V. Hrigoriev, E. T. Bulgakova [2], and others), the history and contemporary trends in design of praxeological models in education (L. Y. Monakhov, V. S. Fedotova [7] and others).

\section{The Presentation of the Material}

We state that the concept of "praxeological culture" is kind-generic. We felt it was necessary, first, to consider the term "culture" as a generic, for disclosure of the nature, the main characteristics of this concept, in accordance with the laws of formal logic. To characterize the essence of praxeological culture of the future teachers, we need to analyze the various points of view on the notion of "culture" and then describe the main approaches to the definition of "praxeology". The next step in our research is clarifying the characteristics and structure of the notions of "praxiological culture" and "praxeological culture of the future teachers".

The study and analysis of the academic literature has shown that the problem of cultural education of the person still causes debate among scientists. The diversity of approaches to the solution of this educational problem is substantiated by the fact that the category "culture" has different interpretations.

So, M. Popovych noted that culture is a huge continent, in which a person lives, culture, in his words, it is not only we, but it is more than we: "None of the most brilliant, the most educated, the most sensitive to human passions, pain and joy person cannot embody the entire nation with its culture. In each person, as the sun in a drop, some facet of all-human achievement is reflected and shone." According to the scientist opinion, culture need to be mastered in order to understand infinitely deep meanings attributed to all its mysterious sign system [8, p. 175]. 
According to T.O. Dmytrenko and K.V. Yaresko, the general culture of a person is in the culture of his or her behavior. An important characteristic of a personality, according to the opinion of scientists, is the culture of work and ability to make qualitative changes in the life of $[4, p$. 14]. Supporting scientists' point of view, we remark that for future teachers in modern educational institutions, the development of culture must be provided by teachers, who with their own example should establish the ideals of a cultural person and with their own activities are changing the environment in a positive direction.

Despite the ambiguity of the proposed solutions and approaches to the definition of culture, the majority of scientists have come to the conclusion that the spiritual and material forms of culture which were created by previous generations are its essential content. We also remark that today culturological approach in pedagogical science is presented in a great diversity.

Open demonstration of orientation on values of humanism allows modern scientists to add new features to the theoretical apparatus, including: students' culture development (L. Malenkova, N. Shchurkova); ideas of culture of peace in the education system (V.Sitarov); culturological aspect of education in its relationship with anthropological assumptions (M. Weber, D. Likhachev, M. Meterlink, I.Fuko, V. Frankle, G. Marcuse, K. Jung, M. Yampolsky and others).

Methodological key to the definition of the future teachers' culture is the concept of culture, the concept of cultural education of a person, and also recognition of the fact that the culture of a man who has not only certain knowledge, but also causes qualitative changes byhis or her activity, is one of the spheres of human life.

With the concept "culture", that has a multicomponent structure, the notion "praxeological" is closely related. In addition, consideration of this notion through the synonymous words "praxeology" and "praxiology", and, accordingly, its functional context, is still controversial [6]. Therefore, this discrepancy in the spelling of the concerned concept in the future may explain the differences in points of view on the concept of "praxeological culture". So ,D.N. Deviatlovskiy, V.V. Ignatova wrote that the term "praxiology" (Greek "praxis" (action, practice) in the literal translation is, "knowledge about the action", cognition of practice in its philosophical sense, that is, to obtain the most general information about the fact that the man does [3]. Unlike "praxiology", category "praxeology" (lat. "praxeus" - action, act) is created at the intersection of sciences (philosophy, sociology, economics and others) and in the modern sense is a science about the principles of human behavior at different combinations of conditions from the point of view of the establishment of effectiveness.

Roderick T. Long states the same in his article «Praxeology: Who Needs It»: «Praxeology is the study of those features of human action that can be grasped a priori. Praxeology "invades the field of philosophy" because it is in fact a branch of philosophy, and specifically of metaphysics.
It is not a "substitute for morality" because it is concerned merely with identifying the principles that govern human action and not with evaluating such actions - though of course praxeological considerations will have to inform that branch of philosophy that is concerned with evaluation, namely ethics» [9, p.305].

We emphasize that the very term "praxeology" was introduced into scientific circulation by the French sociologist A. Espinas (1890), but the fundamental basis in the development of this new science was founded by the Ukrainian scientist Evgeniy Evgenievych Slutskyi (1880-1948). In particular, in 1926 he published the "Study of the problem of constructing formal praxeological fundamentals of the economy". The founder of the theory of marginal utility Ye. Slutskyi was first who carried out a systematic analysis of the theorists' concepts of marginal utility (E.Beum-Bawerk, L. Walras, F. Viser, U. Jevons, K. Menger, and others) and considered the psychological bases of the theory of marginal utility, explained the concept of the value and utility, found elements of the theory of human behavior, the complexity of the system of their interests, etc. It was Ye. Slutskyi who defined praxeology as a general theory and its main formal ontological notions "system", "system state", "system settings", "the state space of the system", "free memory on the system", "optimum", "conductor of the system", "power of system conductor", "passive changes" (which are independent from the "conductor"), "situation" as the state of the system in combination with the "perspective", etc. To our mind, this proves the main difference of the categories "praxeology" and praxiology". It is interesting to note that the name of the Ukrainian scientist Ye. Slutskyi, his contribution to the development of praxeology as a science is not mentioned in most of contemporary works. For example, in a modern textbook "Pedagogical praxeology" [5]. I. Kolesnikova recalls the contribution to the development of praxeology of such scholars as Austrian economist L. Mizes "Human action" (1949), Polish philosopher and logic T. Kotarbinskyi "A treatise on the good work" (1962) and others, but the marginal utility theory, the author of which is Ye. Slutskyi, was not mentioned.

In modern dictionaries the term "praxeological culture of the future teachers" cannot be found. But this does not mean that the content of this term is not represented in pedagogical science. So, we can say that the origin and justification of this concept we have all the necessary historical and pedagogical bases, because the dependence of improvement of the environment on the successful and active actions of a creative Person pervaded the works of the founder of theoretical pedagogics Yan Comenius (in particular, "Universal method"), which influenced the scientists studying regularities of fruitful pedagogical activities. Yet, they are "the ABC of action" by I. Pestalozzi, the idea of learning optimization (Yu. Babanskyi), as well as comprehensive and systematic approach in the theory and practice of education.

Historical transformations of activity philosophy from 
transcendentalism to praxeology is represented in the fundamental monograph by $\mathrm{O}$. Liovkina, praxeological aspects of multiculturalism implementation in the Ukrainian society are revealed in the monograph by S. Drozhzhina, praxeology of a global world creation - in the monograph by I. Pogorska, pedagogy of reflective praxeology - in the monograph by I. Guzenko and others. Among the foreign authors we can mention the publications by Bruce J. Caldwell, Karin Anna Petersen, Murray N. Rothbard, Roger Frantz, Robert Leeson, Staf Callewaert and others. Thus, in the paper «Praxeology and its critics: anappraisal» on this account Bruce J. Caldwell points that «There is no question that praxeology is a novel methodological approach» $[1$, c.377].

Roger Frantz, Robert Leeson "use" praxeology to do research: «Praxeology is the theory of (purposeful) human action. The methodology of praxeology - i.e., the way the theory of human action is developed - is by means of logical deduction or aprioristic reasoning beginning from the self-evident necessarily true: i.e., apodictic» [10, c.79-80].

The research by V. Maiboroda is devoted to the important problem of outlining the tasks of the pedagogical praxeology, updating and detailing the substantive component of the categories of this science, revealing the essence of students' praxeological training as a obligatory component of the program for education and qualification level, in particular, formation of skills and subskills of students' professional activity.

Recent dissertation works present such aspects of research: praxeological approach to the development of reformation activity skills has been presented (D. Poliak); praxeology role of organizational culture has been defined (S. Safonovsky, T. Chervonna); praxeological meanings of the space-time continuum of culture have been revealed (Ye. Barkova); praxeological aspects of scientific space have been grounded (L. Ryzhko); the problems of new scientific disciplines and directions the subject area of which comprises the phenomenon of upbringing methodology in "upbringing praxeology" as a part of "pedagogical praxeology" have been presented (O. Titova); praxeological dimension of citizenship culture has been studied (Ye. Kazakov, T. Chegodaieva); the essential content of the concept "rational style of learning activity" has been defined, pedagogical technology of formation of university students' learning activity rational style has been developed (O. Tareva); praxeology as a methodology that considers the ways of activity (including mental) from the point of view of their practical properties has been developed ( $\mathrm{T}$. Zhyvokorentseva); it has been proven that innovative and socially-creative nature of modern education is specified with making the axiological praxeological component of education the forefront of educational process (A. Prokopenko); the necessity for establishment of national praxeological educational concept of the state has been emphasized (O. Yankovich) etc.

However, the theoretical understanding of the various aspects of higher pedagogical educational institutions students' upbringing in conditions of diversification of education highlighted a number of contradictions of research and practical nature:

- between the implementation of the main objective of upbringing - the formation of ideological orientations, adequate to the principles established and approved at the present stage of coevolution paradigm of the society sustainable development - and the replacement of ideological-axiological, methodological approaches to the organization of effective activity by their rational operationality, instrumentality, by certain techniques that are context and situation dependent and are not generally recognized and relevant to productive established standards of culture;

- between the necessity of formation of the goals achieving ability, motivation of problem solving within institutionalized and socially acceptable norms, rules, traditions and still existing reproductive, object-oriented system of education and upbringing, which hinders the formation of a sound worldview and cultural code of modernity;

- between greatly necessary process of upbringing and development of skills of classification, taxonomy, evaluation and constructive criticism of values, norms and principles, which are not constant and which change every time, retrospectively are understood and measured under the conditions of explosive growth of the available information volume, the complexity of opportunities for structuring, systematization of knowledge from data to meanings and the transfer of estimates from the objective, real world to the informational level;

- between the growing unity of substantial-operational attributes of pedagogical education (learning - students' ordered system of knowledge acquiring, upbringing - a system of values, praxeology -a system of skills necessary for successful implementation of social roles and tasks related to the communication, professional activity and life support) and almost complete lack of implementation of praxeological norms and principles of maximum, optimal organization of upbringing work;

- between having gained practical experience in organization of effective, fruitful, productive, effective upbringing work with students and insignificant volume of reflection and proposals of pedagogical conditions, models, technologies of creating cultural patterns of successful activity.

Thus, the main contradiction which led to the study, is a certain lack of relevant methodological approaches and substantiated the theoretical-methodological foundations, principles and conditions of knowledge transformation into praxeological culture as a pedagogical phenomenon.

The main of the research concept is the idea of integral understanding of the essence of the students' cultural sensitivity upbringing process in which along with the traditional components of the upbringing and formation of objectives and results achievement motivation estimating-critical component is of special importance as a 
factor of complex solution of the tasks of modern education, as the key for successful implementation of self-directed effective practice.

If in the pedagogical sense, upbringing is a specially organized and managed process of person formation, which is realized by a teacher in the educational institutions and is directed to the development of personality, praxeological culture upbringing should be considered in several planes of reflection:

1. In the plane of the objectives, contents and organizational and managerial conditions of modern education. On the objectives of upbringing, they are the pre-defined (forecast) results of youth training for implementation of all the essential activities. The development of modern society is characterized by very intensive growth of information and technical level, which not only requires certain demands from its members. It also leads to the nomination as the main goal of the ideal upbringing of the objective need for development of a comprehensive harmoniously developed personality, which is capable of innovation to improve their health, logical thinking, communicative skills, spiritual and sacred well-being and to acquire the skills of practical realization of their knowledge and meanings in the effective activities. On the basis of M. Weber's defining of human nature rationality, its manifestations in the society, the differentiation of the ideal types, we can state that modern students acquiring the skills of organization and evaluation of practical activity, which is all the time technically, operationally complicated, is the principal task of upbringing in the higher school.

In the plane of the content the praxeological culture upbringing should be seen as the totality of systematized knowledge, skills, attitudes and beliefs, values and a certain level of development of the cognitive powers and practical training, which has been achieved by the subject of upbringing in preliminary preparation. The dialectical unity of purpose and content of upbringing is important as well, it is determined by historical character of development that changes the basic components of both the aim of upbringing and its content (value-motivational, cognitive personality experience, the experience of creative activity and system-motivational and emotional relationship). This statement is based on the conclusion by T. Kotarbinskiy that praxeology covers three groups of problems (analytical description, characterization, classification and systematization of practical actions; study of conditions and the laws that determine the efficiency of actions; the study of genesis and development of various activities, directions of improvement and regression, moved by the power of tradition and creativity).

In various as for substantive reduction studies, as a rule, organizational and management conditions are determined as an independent object in the process of upbringing, that, in our opinion, breaks the integrity of upbringing, since the experience of activities implementation (practical experience) is a part of all components of the objectives and contents of upbringing and is a basic culture of the person.
Moreover, without the inclusion of practical acquiring of upbringing mechanisms and "the principles of perfect activity" (T. Pshcholovskiy) modernization of learning and upbringing will remain a project. Thus, in the first component, which is a specific phenomenon, the result of social human development and culture of feelings, having the peculiarity - the assessment of the world, the activities, the actions of people, - requires practical skills of ascent from simple opinions, statements and interpretations to rational and reasoned, intellectually correct logical operations that constitute a meaningful evaluation. In the cognitive component the knowledge of the activity ways of knowledge about the scientific picture of the world acquisition, on the one hand, need practical means of learning, and, on the other hand - external (operational-organizational) and internal (intellectual-creative) ones require skills of their use and further development.

Thus knowledge about the organization and forming of intellectual and practical skills (praxeology) will make creative transformation of process of youth teaching and upbringing at first, and then the reality transformation. So, the skills of knowledge transfer to a new situation; the vision of a new problem in a familiar situation, the new functions of the object, independent combination of known ways of activity in the new mechanism, finding different ways of solving problems and alternative evidence that will promote the basic culture upbringing of students, who study in a higher pedagogical educational institution.

2. The second aspect of the research refers to the objective plane of culture, surely, in its pedagogical sense, and makes it possible to overcome the stereotypical image of the knowledge, detached from specific existing problems that require not only answer to the question "What is this?" but also the organization of thinking and reflection concerning the questions like "Why? How?". If we trace the dynamics of culture interpretations, the variety of its manifestations will be understood, as in a broad sense, it means everything that the man has made in the various branches of activity, unlike animals. In this sense, the main thing that unites all of interpretations, in our opinion, we should understand culture as a system of non-biologically established mechanisms which "programme" human activities and occur as variable in time and space ideas principles, norms, ways, methods, procedures of activity defining the relationships of man and the world. Thus, to become a cultured person means to enter the world of human transformative activity.

Since culture in various branches of activity reveals specific regular internal relations, there is a need to think of the system of culture (environmental, political, civil, moral-ethic and others). Taking into account the positions of "morphology of culture" representatives (O. Spengler, A. Toinbi and others) about the transition to the internal integrity, independence, self-management of culture system (synergetic doctrine), it should be noted that the activity and the culture change as for the internal forces, and under the influence of other factors, in particular, learning and 
upbringing. We consider it appropriate to explore the purposeful influence on the culture, in particular its part regarding the implementation of practical activity.

3. Within interdisciplinary connection the research topicality requires touching the theoretical foundations of the activity with its functional units: motives, goals, ideas, programs, information framework of the activity, subsystems of qualities important for activity. Moreover, its study serves as a heuristic tool for each activity, which always has a certain conventionality. We mean that the reduction for the analysis of each of the species does not imply their ontological autonomy. The necessity of broadening of scientific-pedagogical apparatus and methodological tools for knowing the real practice of the higher pedagogical education implies the consideration of such complex processes as the dynamic development of globalization processes in the educational sphere, the expansion of multicultural educational space, strengthening of professional risks in pedagogical work and others. In its turn, this requires carrying out an analysis of pedagogical rationality at the present time, that is connected with the consideration of the value of the pedagogical activity, the study of its relations with a number of other activities, including such activities of a future teacher as psychological, social, organizational, managerial and others. Such study presents a number of specific new types of attitude to the student youth's activities, the acquisition of the certain toolkit in upbringing process. This toolkit is formed at the intersection of the variety of actions and system of deeds.

Examining the process of upbringing of students' praxeology culture, on the first hand, we should base on specific regularities of specific activity, represented by learning and professional training and, on the second hand, we should understand that praxeological culture of students deals with the willingness to implement rather specific professional activities - management of the educational-cultural processes. That is why acquiring the program of professional activity involves the formation of not only ideas about the composition of activity, about ways of execution of certain actions, operations, procedures, which in the structure of activities are united by the aim and are structurally subordinated, organized in time and space, but also the development of value-semantic understanding of effective practical activity, which is based on the knowledge of substantive ("what"), operational ("how"), and semantic ("what for") levels of understanding. Therefore, we consider the culture of practical activity, which should be brought up as an integrated conceptual-methodological, methodical and praxeological system, reflectively related to learning, upbringing and with all other spheres of modern and future life.

Nowadays such notions as "efficient teacher", "pedagogy of success" are developed, active methods and technologies are applied and enhance the success of the pedagogical activity of the teacher. Thus, the mentioned above works, as well as the theories of activity (S. Rubinshtein, A. Leontiev), didactic pragmatism (J. Dewey, G. Kerchensteiner and others), functional materialism (V. Okon), operatonal structuring (K. Sosnytskyi) and others - have a significant impact on grounding of such notion as "praxeological culture of the future teachers", because they have a common range of problems- development of human potential and the search for manifestations in the future effective educational influence on change and design of educational space. The necessity of broadening scientific-pedagogical apparatus and methodological tools for studying the real practice of higher education implies the consideration of such complex processes as the dynamic development of globalization processes in the educational sphere, the expansion of multicultural educational space, strengthening of occupational risks in pedagogical work and others. In turn, this requires an analysis of pedagogical rationality at the present time that is connected with the consideration of the value of pedagogical activity, the study of its relations with a number of other activities, including such activities of future teachers, as psychological, social, organizational, managerial, etc. Such study presents a number of specific new types of attitude to the future teacher activities, their acquiring particular tools in the process of training and education in higher school, and those tools are formed at the intersection of the variety of actions. So, a future teacher, who aims at getting higher education for further work in the educational sphere, today should acquire certain competencies that enable to effectively educate and teach the next generation at a high professional level. However, these competencies (among which - personal-social, professional, instrumental, specialized-professional etc.) are only the initial stage, the starting point, which allows the future teachers to develop to a high level - the level of culture, in our case -praxeological one.

A special place in the structure of praxeological culture of the future teachers is taken by the culture of their needs, motives and ideals that facilitate a specific activity. It's necessary to remark that the high level of praxeological culture involves deep theoretical knowledge, that is, the acquisition of knowledge on the categorial apparatus of praxeological, principles of effective activity analysis, goal-setting, decision-making that helps to get a definite result, and the like.

However, theoretical knowledge itself does not always help to reach a high level praxeological culture. It is necessary that on the basis of knowledge of pedagogical praxeology, the firm beliefs would be formed (strength of knowledge, its depth, the willingness to commit certain actions, etc.), for the pursuit of activity efficiency was internally future teacher's acquisition.

Besides the theoretical component of praxeological culture, which comprises the content of the future teacher's intellectual sphere, occupies an important place in the emotional-volitional component, which includes elements such as the adequacy of reflection and expression in feelings of appropriate attitude to the efficient activity of the teacher, which brings qualitative changes, the unity of approving an acceptable solution and its execution, etc. 
Objective indicator of the high level of praxeological culture of the future teachers is their culture, too. In a broad sense it covers compliance with certain requirements for pedagogical work, conscious performing of professional activity aimed at achievement of educational activity results; and in a narrow sense, for grounding and making norms of maximum feasibility of pedagogical activity on the basis of broad generalizations of effective teaching experience accumulation.

Thus, praxeological culture of the future teachers is a complex interaction of elements. Both effectiveness and the forms for its implementation chose by student youth who chooses the profession of a teacher can be observed through the various activities of the future teachers.

There are three main processes which are carried out by the teacher in the field of praxeological culture:

- transfer of elements of an effective, productive cultural activities for students;

- simulation of a situation of success in a variety of behaviors, effective achievement of results through a system of efficient action;

- creation of new forms of pedagogical work, which leads to the effectiveness of the teaching work through innovation in pedagogy.

These processes contribute to the stabilization and improvement of the quality of each teacher's work as the subject of positive changes in the education system, which promotes its progressive development.

As pedagogical education in universities is always one of the main transmission mechanisms of professional culture in general, and, praxeological in particular, these processes should always add novelty: for example, in the creation and discovery of previously unknown active technologies and effective techniques that are more efficient than those techniques and technologies that are considered classic, time-tested; observation of new methods of pedagogical activity, which lead to the success of both the teacher and the pupil; the discovery of new ideas in the field of cultural person education through the appliance of new, more efficient methods, etc.

In this case, inactivity of some teachers, their being in a "comfort zone", which is observed today, shouldn't influence the cultural-educational space. Necessary for future teacher's successful activity professional and personal qualities are acquired and achieved only on the background of initiation to praxeological culture, as it is dangerous for the pedagogical community if a specialist is without a developed emotional-volitional sphere, without awareness of cultural values of pedagogical creativity.

Therefore, an objective indicator of praxeological culture of the future teachers comprises positive achievements in the practical activity in the sphere of educational services that can be diagnosed among students already during the first educational practices.

\section{Research results}

Objective indicator of students' praxeological culture is their general culture of behavior. In a broad sense it covers compliance with specific requirements for different types of activity, conscientious execution of instructions, aimed at the achievement of results of educational-upbringing activity and in a narrow sense, for grounding and making norms of maximum feasibility of the actions and deeds on the basis of broad generalizations of accumulated experience of effective activity of the person who chooses the profession of a teacher. Thus, praxeological culture of higher pedagogical educational institutions students is a complex interrelation of elements.

So, praxeology culture is the organon (a tool, a method) for practical activity and in this sense makes it possible to renovation of a holistic continuum picture of the world and professional educational activity by the future specialist on the basis of theoretical-methodological and methodical information turning into the plane of practical use, namely:

- defines the leading methodological principle of practical activity relevant to the contemporary conceptual framework knowledge, which is formed in such a way that the assimilation of knowledge occurs through the definition of categories and concepts that are convenient, concise and understandable for the student;

- overcomes in practical learning, organization and structuring of different substantial (declarative) and operational (procedural) knowledge contradictory differences, their complex and dialectical unity;

- minimizes the efforts of students on the practical implementation of new knowledge by means of its interrelation with already existing knowledge, life world, certain socio-historical context, as without sufficient level of praxeological culture neither the values of life, nor operational values of development cannot be included into new knowledge in the conceptual and ideological framework;

- will become the basis of interiorization in the practical activity of the future teachers of the heuristic potential of the inter-disciplinary content of other branches of science, as it will make the process of building models and algorithms of upbringing and learning like cybernetic systems of problematic environment, philosophical criteria of scientific knowledge effectiveness, synergetic projects of new ideas generating due to the expansion of interpretation space etc.;

- will guide the specialist's practical training on effective ways of self-development and self-upbringing, which allows at the macro-level (construction of upbringing methodology) to try out different ideas on sustainability, adequacy of time-saving resource etc.; at the mesa-level (development of upbringing programs and methods, upbringing affairs) to try a new idea in various forms, without compromising it immediately and in general for the unsuccessful implementation, and to search for the ways of effective implementation; at the micro-level (the practical implementation of skills and subskills, doing deeds) to 
check the algorithm of finding solutions and solving problems, tasks and intellectually move from opinions, interpretations to analysis, synthesis and meaningful assessments by means of tools;

- and, finally, forms evaluation criteria in practical development and analysis of ideological orientations and values.

Taking into consideration, that the acquiring of the substantive knowledge in the process of upbringing has a great experience of organization (the traditional system of upbringing, which is based on knowledge-subject content of education, in which the substantive definition of the world picture and spiritual values prevails), it was almost completely relevant to the theoretical description of activity, but is not easy to use in practice, Therefore, the willingness to implement the programmes of practical activity on the intellectual level should be formed.

\section{Conclusions and Perspectives of Further Research}

In the works of scientists the attention is paid to the fact that the formation of praxeological culture of the future teachers should be under special consideration.

Achievements in the future of the teacher in a broad sense will be reflected in the culture of all mankind. It is praxeological culture of the future teachers that is an integral part of their professional pedagogical culture. The function context of praxeological culture of the future teachers is the development of the student's personality and self-development, self-education.

Such components as intellectual, emotional-volitional and behavioral ones should bein the basis of praxeological culture development. Prospects of the study are the development of a praxeological approach as a methodological one to address the issue of the education of future teachers, their focus on the effectiveness in the future pedagogical activity.

\section{References}

[1] Bruce J. Caldwell; Praxeology and its critics: anappraisal; History of Political Economy 16:3, 1984, CCC 0018-2702/84, pp.363-369.

[2] Bulgakova Ye. T. Praxiological situations as the means of pedagogue's realization of personality-oriented approach in teaching teenagers; Materials of 13th Scientific-Technical Conference; - MMDD-2009:. - URL: http://abiturient.ncstu.ru /Science/conf/past/2009/ region13/theses/ppsl/073.pdf. - (date of turning: 25.04.2014).

[3] Deviatlovskiy D.N., Ignatova V.V. Definition of the notion "praxiological skills of the future specialist"; Fundamental researches; - MMDD-2012; URL: www.rae.ru/fs/?section $=$ content\&op=show article\&article id $=9999297$ (date of turning:25.04.2014).

[4] Dmytrenko T. O., Yaresko K.V. Methodological basics of social pedagogics; MMDD-2003. $-32 \mathrm{p}$.

[5] Hrihoriev B.V., Chumakov V.I.. Praxeology or how to organize the effective activity;- MMDD-2002. - 144 p.

[6] Kolesnikova I.A., Titova Ye.V.. Pedagogical praxeology: study guide for students of higher pedagogical institutions; Izdatelskiy tsentr "Akademiya" - MMDD-2005. - 256 p.

[7] Monahova L. Yu., Fedotova V. S. Praxiology and praxeology in historical-methodological discourse; Scientific Review; MMDD-2011. - № 3. - pp. 76-87.

[8] Popovych M. V. Essay on History of Ukrainian Culture; MMDD-2001. -728 p.

[9] Roderick T. Long; Praxeology: Who Needs It; The Journal of Ayn Rand Studies Vol. 6, No. 2; MMDD-2005, pp.299-316.

[10] Roger Frantz, Robert Leeson; Hayek and Behavioral Economics: Archival Insights into the Evolution of Economics; Palgrave Macmillan; 2013, 368 p. 